\title{
Blockchain-Based ICOs: Pure Hype or the Dawn of a New Era of Startup Financing?
}

\author{
Lennart Ante ${ }^{1,2, *(\mathbb{D}, \text { Philipp Sandner }}{ }^{3}$ and Ingo Fiedler ${ }^{1,2}$ (D) \\ 1 Faculty of Business, Economics and Social Sciences, University of Hamburg, Von-Melle-Park 5, \\ 20146 Hamburg, Germany; ingo.fiedler@uni-hamburg.de \\ 2 Blockchain Research Lab gGmbH, 20354 Hamburg, Germany \\ 3 Frankfurt School of Finance \& Management, Adickesallee 32-34, 60322 Frankfurt am Main, Germany; \\ email@philipp-sandner.de \\ * Correspondence: lennart.ante@uni-hamburg.de; Tel.: +49-40-42838-6454
}

Received: 23 October 2018; Accepted: 13 November 2018; Published: 21 November 2018

check for updates

\begin{abstract}
This study explores the determinants of initial coin offering (ICO) success, where success is defined as the amount of capital a project could raise. ICOs are a tool for startups in the blockchain ecosystem to raise early capital with relative ease. The market for ICOs has grown at a rapid pace since its start in 2013. We analyze a unique dataset of 278 projects that finished their ICOs by August 2017 to assess determinants of funding success that we derive from the crowdfunding and venture capital literature. Our results show that ICOs exhibit similarities to classical crowdfunding and venture capital markets. Specifically, we identify resemblances in determinants of funding success regarding human capital characteristics, business model quality, project elaboration, and social media activity.
\end{abstract}

Keywords: initial coin offering; blockchain; venture capital; crowdfunding

\section{Introduction}

Understanding the role of blockchain-based initial coin offerings (ICOs), which are claimed to provide startups with a new form of financing, is of increasing importance both from a practical (Clayton 2017) and a scholarly perspective (Conley 2017). Raising funds via ICOs is a very recent phenomenon, with the first such offering having taken place in 2013. Especially over the last two years, the number of ICO projects and the amount of funding raised have grown at a rapid pace and attracted a lot of investors, with over $\$ 15$ billion raised so far.

The ICO market has so far been characterized by very high yields for investors and, at the same time, a lack of proper regulation. It could be argued that the ICO market has developed into a bubble that could burst, like the dot com bubble (Wheale and Amin 2003), or that the exponential growth of ICOs can solely be explained by the dawn of a new era of corporate financing. While certain return rates for investors are at an abnormal level that is unlikely to be sustained in the future, there are also good arguments why the current hype about ICOs is at least somewhat justified. One major reason is that via the use of the underlying blockchain technology, ICOs enable startups to raise funds from investors around the globe without the need for minimal contribution levels. Another reason is that the tokens sold can usually be transferred immediately and traded on global cryptocurrency exchanges that provide liquid secondary markets and operate $24 \mathrm{~h}$ a day and seven days a week.

There are three ways of looking at ICO financing: From the perspective of (1) startups; (2) individual investors ${ }^{1}$; and (3) social welfare. When approaching the topic from the perspective

1 Legally, the term 'investor' may not be universally applicable, as ICO contributions, strictly speaking, often constitute donations. 
of startups, the main questions are how ICOs can help finance business ventures and how they are best applied. Individual investors focus on success rates and on the return on their invested capital. From the social welfare perspective, the angle of analysis is on the benefits and costs that ICOs entail for society, how much market value they help create, and how they could be regulated.

Adhami et al. (2018) analyzed success determinants of 253 ICO campaigns and find that code availability, presales, and specific services (like profit sharing) increase the probability of campaign success. Fisch (2019) used a sample of 238 ICOs campaigns between 2016 and 2017 and found that the underlying technology of a project determines the amount of funding, while venture characteristics are less relevant. Amsden and Schweizer (2018) showed in their sample of 1009 projects between 2015 and 2017 that venture uncertainty is negatively correlated and venture quality is positively correlated to ICO success. The term "success" is somewhat misleading, as it can be applied to funding success, venture success, secondary market access, or return on investment. From the perspective of a startup, the initial funding has the highest relevance, which is why we define success as the amount of funding that a project is able to gather.

In this paper, we tackle the question of whether ICOs are pure hype or whether they represent the dawn of a new era of financing from the perspective of startups and investors by analyzing whether investors in ICOs behave similarly to investors in traditional crowdfunding. Signaling theory (Spence 1973) can be used to explain the relevance of specific information for investments into companies (Ahlstrom and Bruton 2006; Coleman and Robb 2014; Robb and Robinson 2014; Ahlers et al. 2015). Ahlers et al. (2015) point to a research gap regarding the signaling of start-ups towards smaller investments in the context of equity crowdfunding. As ICOs are a very new phenomenon, the same research gap can be found for this specific kind of crowdfunding. For this purpose, we examine the determinants of ICO funding using a unique dataset that includes data on the amount of funds raised in 278 ICO projects through the 3 August 2017 (see Supplementary Materials), and a variety of additional variables for each project. We hypothesize that if ICO participants invest their money based on the expected fundamental value, this constitutes evidence of ICOs being a new form of startup financing; otherwise, the current success of ICOs is perhaps more appropriately described as a hype. We argue that we may speak of rational (i.e., fundamentals-based) investment if the amount of funds raised per project is driven by similar variables as in traditional startup financing, such as team size, project quality in terms of the business model, and project elaboration, or social media activity.

Analyzing investor behavior in ICOs allows us to further add to the current stream of literature on venture capital in two ways: We provide both a descriptive overview of the phenomenon of ICOs and an insight into the variables that startups looking for ICO investments should focus on by analyzing how ICO success depends on a range of factors.

\section{Literature and Hypotheses}

\subsection{Startup Financing}

When starting a venture, the entrepreneur will eventually face the question of how to fund the business. Sources of external finance will often have to be tapped. While debt funding is not always available, there are several options of equity funding. An angel investor, or business angel (BA), is one such source of capital for early-stage startups. Deakins and Freel (2003) describe BAs as wealthy individuals without any family connection to the entrepreneur who invest their money and experience in the venture. Macht and Robinson (2009) find that BAs help the investees to close funding and knowledge gaps, provide them with business contacts, and facilitate future funding. Harrison and Mason (1996) suggest that most BAs do not participate in follow-up funding, which has, however, been disputed in the literature.

Another form of equity financing is venture capital (VC). Venture capitalists collect funding from larger investors and allocate it to startups based on a sophisticated screening process. VC traditionally 
covers the larger and more developed stages of startup funding and does not play a role in deals below three or four million dollars (Kim and Wagman 2016). However, to support young ventures for later deals, many VC funds have started to also engage in seed stage financing, i.e., the early-stage funding typically covered by BAs. According to Kim and Wagman (2016), entrepreneurs will typically lose more of their ownership in the startup if they accept VC as compared to angel capital.

The attraction of outside capital constitutes an inherent problem for startups, as the desired amount of collateral or cash flows simply do not exist and there is a significant amount of information asymmetry (Cosh et al. 2009; Schwienbacher and Larralde 2010; Busenitz et al. 2005) or information cascades (Vismara 2016) with investors. Startups face the problem of signaling their quality at an early stage of development. Baum and Silverman (2004) list three major factors that investors may use to assess the quality of a project: Human capital, social (alliance) capital, and intellectual capital. Crowdfunding offers a way for members of the general public to pool their resources to fund a particular project via the internet (Ahlers et al. 2015), and has become a commonplace way for early stage companies to attract financing in recent years (Hornuf and Schwienbacher 2017). As Griffin (2012) states, the existing forms of crowdfunding can be distinguished by the type of rewards that contributors get in return: Crowdfunding campaigns can be (1) donation-based, without any actual rewards; (2) rewards-based, with non-financial rewards in the form of promotion or services; (3) lending-based, with a financial return like interest payments; or (4) equity-based, with financial return in the form of equity or dividends. Crowdfunding campaigns offer a signal regarding the market potential of a product (Schwienbacher and Larralde 2010; Cholakova and Clarysse 2015). In comparison to investments from angels or $\mathrm{VC}$, crowdfunding must attract investors who are small both in terms of their financial contributions and in terms of their stake in the target company (Malmendier and Shanthikumar 2007). Smaller investors are less experienced than VCs and face higher information costs-a relatively small investment does not warrant weeks of researching the target project (Ahlers et al. 2015).

In the following, we will deduce the group of characteristics that will be used to compare blockchain-based ICOs to the traditional markets of VC and crowdfunding. We build upon results obtained in previous studies for these markets, which are most similar to ICOs in terms of the existing literature and procedures.

Human Capital. In line with existing research on VC (e.g., Hsu 2007; Gimmon and Levie 2010), we posit that the human capital of ICO teams will act as a signal for potential investors, assuming that investors gauge the future success of new ventures on the basis of the team's human capital, which is an important resource for organizational success (Becker 1993; Lee et al. 2001). While larger teams have more human capital, as argued above, team size is also a future cost factor, as the team will be paid from the proceeds of the crowdfunding. Previous research has found that venture capitalists value human capital criteria, such as previous startup experience, education, and managerial leadership experience (Hall and Hofer 1993; Muzyka et al. 1996; Zacharakis and Shepherd 2005). Such criteria serve venture capitalists as team quality indicators in the face of uncertain prospects (Gimmon and Levie 2010). In a similar vein, research has shown that investors also value the founders' social capital (Florin et al. 2003; Stuart et al. 1999). Hsu (2007) showed that the effect of human capital on VC valuations positively depends on the novelty of an industry. This result is particularly relevant to our context, blockchain technology, which is also an emerging technology at the moment, much like the Internet was in the 1990s and 2000s (Iansiti and Lakhani 2017). Ahlers et al. (2015) show that human capital is an important factor for the investment decision of small investors in crowdfunding campaigns. Overall, in line with existing research, we posit that a team's human capital endowment will be positively related to the funds raised during an ICO.

Quality of the business model. A business model connects an idea or technology with its potential revenue stream. As methods to define a business model, Chesbrough (2010) suggests the value and revenue proposition, market segment, structure of the value chain, cost structure and profit potential, value network, and competitive strategy. Zott et al. (2011) showed that the 
literature provides no general and consistent definition of a business model and thus also of its quality. Various determinants of the quality of business models can be identified across the literature, such as the presence of information and communication technologies in the e-commerce literature (Timmers 1998; Dubosson-Torbay et al. 2002), value drivers (Amit and Zott 2001), actual choices by the project (Shafer et al. 2005; Casadesus-Masanell and Ricart 2010), regulatory pressure (Tankhiwale 2009), and discovery-driven experimentation in the strategic literature (McGrath 2010). Technology itself (Chesbrough and Rosenbloom 2002) and technological development and innovation (Calia et al. 2007; Björkdahl 2009) are identified as determinants of quality in the technology and innovation management literature (Zott et al. 2011). Hellmann and Puri (2002) suggest that companies with innovative marketing strategies are more likely to be funded by VC as their products will penetrate the market more quickly. As a successful business model unlocks the realization of economic value from a technical basis (Chesbrough and Rosenbloom 2002), we expect that its quality will be positively related to the funds raised during an ICO.

Project elaboration (whitepaper). We suggest that the availability and quality of a whitepaper, which elaborates on the business project for the information of potential investors, will have a positive impact on the amount of funds that a project is able to raise. A whitepaper for ICOs, which $52 \%$ of the companies in our sample provide, can be compared to the business plan or pitch of traditional projects, as it usually contains all the information that may be relevant for investors. Barrow et al. (2001) describe the business plan as the potentially most relevant aspect for the successful creation of a business. Business plans, or the whitepaper of an ICO, represent the first detailed information that a funding team shares with its investors (Shepherd and Douglas 1999). Cumming et al. (2016) showed that fraudulent crowdfunding projects, a recurring phenomenon, are often characterized by badly drafted pitches. Findings by Ahlers et al. (2015) suggest that the provision of detailed information about risks can increase the likelihood of a successful crowdfunding campaign. Du et al. (2015) show that crowdfunding success can be explained by the amount of information that is disclosed in project descriptions. Chen et al. (2009) investigated to what extent entrepreneurial passion influences VC investment decisions. The authors found that funding success is driven not by the founders' passion, but by their level of preparedness. This suggests that ICO projects with very detailed whitepapers will be more successful. We therefore posit a positive relationship between project elaboration and funds raised.

Social media. Based on existing research in crowdfunding and venture capital, we posit that social media activity, as proxied by the number of followers and the number of postings, will positively influence funds raised at ICOs. At least two transmission mechanisms for this expected effect come to mind (Jin et al. 2017; Yang and Berger 2017): First, social media activity may serve as a marketing channel for announcing ICOs and distributing information about the underlying new tokens. Thus, in line with the "salience view" (Solomon et al. 2012), increased social media activity will lead to increased salience of an ICO, directing potential investors to the upcoming investment opportunity (Sprenger et al. 2014). Second, social media activity may also serve as a positive signal of endorsement from others and act as a mechanism to grow a (social) network and future user base (Lechner et al. 2006; Witt 2004). According to this view, ICO projects with more followers on social media will raise more funds because the positive signal to investors indicates higher levels of social network resources. Indeed, recent research has shown that the amount of funds raised by startups is associated both with the number of social messages and with the number of followers. For instance, Jin et al. (2017) show that Twitter influence (a composite score consisting of the number of followers, mentions, impressions, and sentiment on Twitter) is positively related to the funds raised by early-stage startups. Moreover, they find a quadratic relationship between the number of Twitter posts and funds raised, such that more posts initially increase funding while too many posts harm the outcome. In a similar vein, Yang and Berger (2017) have recently shown a positive relationship between the number of followers and the amount of startup funding. Likewise, Nevin et al. (2017) show that the number of social media posts has a positive effect on funds raised through crowdfunding. 
Cumming et al. (2016) provide evidence that fraudulent crowdfunding projects are less likely to use social media channels. Colombo et al. (2015) suggest that communication between a project and its potential backers has a positive influence on the success of the campaign. Overall, based on this evidence in the context of startup funding, we expect a positive relationship between social media activity and funds raised at ICOs.

\subsection{Hypotheses}

Our general hypothesis is that ICO participants invest rationally based on fundamental value expectations. We break this general hypothesis down into four hypotheses that can be tested empirically. Each hypothesis is based on findings from the traditional VC funding and crowdfunding literature, which we discussed above, and which we expect to confirm with respect to ICO funding if investor decisions are driven by fundamental value expectations.

Hypothesis 1 (H1). There is a positive relationship between the amount of funds raised and the company's human capital characteristics, which we operationalize as (a) team size, (b) team network size, and (c) the number of advisors.

Hypothesis 2 (H2). There is a positive relationship between the amount of funds raised and business model quality, which we operationalize as a score variable determined by an industry expert for each project for the respective form of the projects token-based business model (infrastructure, financial, or utility model).

Hypothesis 3 (H3). There is a positive relationship between the amount of funds raised and project elaboration, which we operationalize as (a) whitepaper availability and (b) a whitepaper score based on a whitepaper's number of pages and citations.

Hypothesis 4 (H4). There is a positive relationship between the amount of funds raised and social media presence, which we operationalize as a score based on the number of Twitter messages and the number of Twitter followers, as Twitter is the most widely used social media channel across the projects covered by our sample. Activity levels on Facebook, Reddit, and Bitcointalk are used as control variables.

\subsection{Blockchain Technology}

Blockchain represents an emerging technology that is among the most promising and potentially most disruptive technologies in the future. It was first introduced in October 2008 by an unknown person or entity using the name Satoshi Nakamoto, who presented it as part of the proposal for Bitcoin, its first suggested application (Nakamoto 2008).

A blockchain is a distributed register to store static records and/or dynamic transaction data without central coordination by using a consensus-based mechanism to check the validity of transactions. In simple words, it is a database in which transactions are recorded and which is simultaneously shared among all parties in a participating network. Data is stored in fixed structures, "blocks", which are always linked to the latest block that has been added to the database. As all blocks are linked together in a chain, the entire history of transactions can be accessed and retraced. The verification of each transaction results from the consensus of the majority of participants in the network, without the involvement of any intermediary. In the Bitcoin world, for example, transactions are validated by so-called miners, which are network members with high-level computing power. In order to validate transaction blocks, complex coded problems must be solved. The miners' efforts are then rewarded with Bitcoins (Nakamoto 2008).

The main goal of the technology is to create a decentralized environment where no third party is in control of the transactions and data. Simultaneously, it allows for transaction platforms that are highly secure, cheap, fast, and less prone to error. This innovation will change not only the interaction 
between individuals and organizations, but also business-to-business (B2B) collaboration, raising the overall productivity of the economy. The potential benefits of blockchain are not restricted to economic matters, but extend to offering solutions to social, political, legal, and health issues (Linn and Koo 2016; Scott 2016; Osgood 2016; De Filippi and Hassan 2018).

While blockchain is much acclaimed for its potential to deliver solutions to a wide range of issues, the adoption of the technology entails significant risks and challenges that require awareness. One of the most significant risks arises from future government regulation, a factor that is crucial to the success of the blockchain industry. We may expect the new technology to be much more heavily monitored and regulated in the future, and these new regulations may either facilitate or slow down the adoption process. Furthermore, several technical challenges and limitations have been identified and must eventually be addressed (Puthal et al. 2018; Joshi et al. 2018). Among them are the limited throughput, the time required to complete a transaction, and high data volumes. Moreover, users worry about a number of security threats. Especially, in financial contexts, there is concern about hackers, identity theft, and money laundering (Ante 2018). All in all, the technology is still evolving and maturing. As ever, more individuals and organizations are investigating and experimenting with it, and new recommendations on how to solve the current issues are made each day.

\subsection{Blockchain-Based Startup Financing}

An increasing number of startups in the blockchain ecosystem use ICOs to raise early-stage financing. Instead of going for initial public offerings (IPOs), which are expensive and highly regulated, startups often issue a blockchain-based token and distribute it across investors in proportion to their respective investment. So far, ICOs are regulated only very lightly, if at all. This allows for fast processes and low operational cost.

In order to conduct an ICO, a token-based economy must be generated in which the blockchain token has some form of value for investors. Figure 1 provides an example of a token-based economy and the initial distribution of tokens. A company builds a product or a service around a token. The token is used as a project-specific currency, some form of utility (utility token), or a security (security token) that can provide some form of profit participation to investors. Utility tokens are the most widely used token structure for ICOs. They possess some form of utility to token holders, like a software license, which enables startups to bypass security regulations for their token sale. Security token sales are less common, as they entail much higher legal costs and preparation and most cryptocurrency exchanges do not hold the relevant licenses to trade securities, while regulated stock exchanges cannot accommodate tokens yet. This paper focuses on utility tokens, as our sample mainly consists of utility tokens. In order to access the product or service of the ICO project, users will need to possess the specific token. The project simply generates the tokens and offers them to investors for purchase in the ICO. Utility tokens do not represent equity or dividend rights, so they allow startups to obtain finance while retaining full ownership of the company. ICOs are usually carried out at a very early stage of the development process. Investors expect the tokens to increase in value as they speculate that demand for the tokens will increase given the fixed or limited supply.

With the introduction of Ethereum and smart contracts, decentralized computer protocol can automatically be executed upon predefined terms. This enables crowdsale-specific smart contracts that are deployed on the blockchain and contain all crowdfunding details in the form of computer protocol. Newly created tokens on the Ethereum blockchain are automatically distributed to investors upon the successful deposit of funds (in the form of cryptocurrency), and once the crowdfunding goal is reached, all additional payments are automatically returned. Blockchain technology enables various technological innovations in the field of crowdfunding, as the decentralized architecture in combination with low transaction fees permits individuals from anywhere to participate in an ICO with as small an amount as they desire. 


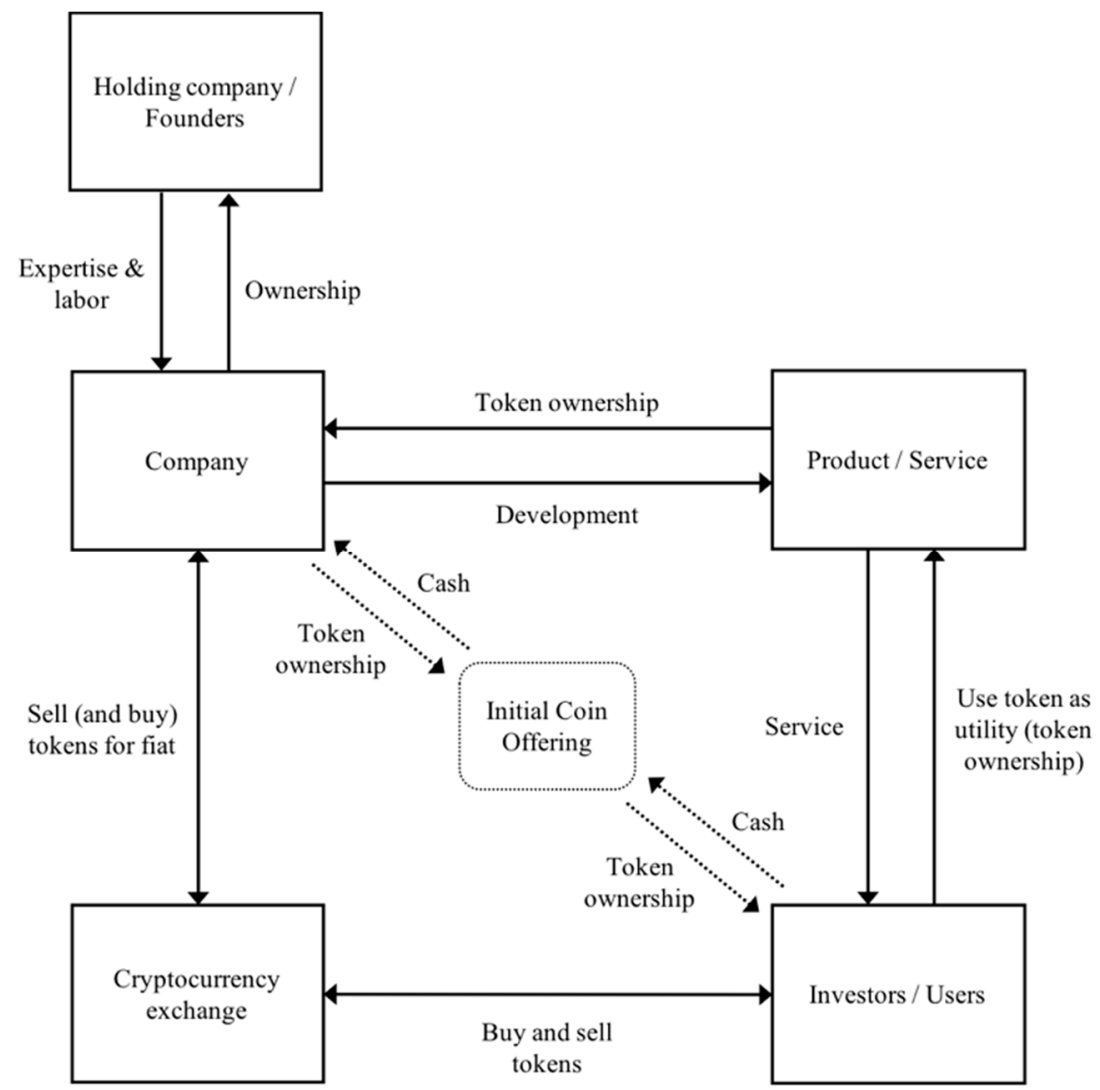

Figure 1. Token-based economy and initial coin offering (ICO).

\section{Data and Methodology}

\subsection{Data Sources}

To identify blockchain-based crowdfunding projects, an explorative analysis of the ecosystem was conducted. The online forum, Bitcointalk ${ }^{2}$, serves as a platform to announce new projects and to communicate with potential investors. Project details, like crowdfunding date, team information, amount of funding, or token distribution, were sourced from Bitcointalk, where available, or the official web presence of each project. To this day, there is no comprehensive knowledge base that lists information on all ICOs, so most information had to be retrieved manually. Social media statistics, such as likes, followers, or subscribers, for the platforms of Twitter, Facebook, and Reddit were imported directly from the application programming interfaces (APIs) of each social media website.

Our dataset consists of 278 projects that finished their ICO between July 2013 and August 2017. The sample comprises all ICOs during that period for which we were able to collect information on all the variables. Due to a lack of transparency and public data, a number of ICOs had to be omitted from the sample.

\subsection{Operationalization of the Variables}

Dependent variable. This paper relies on the amount of funds raised (in USD) as the dependent variable, i.e., as our measure of ICO success. Since the variable is highly skewed, in the regressions, we use the natural logarithm, in line with existing research (Alexy et al. 2012; Sandner and Block 2011). As projects that finance themselves via an ICO are usually funded in the form of cryptocurrency,

2 https://bitcointalk.org. 
the actual fiat value of the funding depends on the exact point in time at which the prices of the cryptocurrencies, which fluctuate strongly (Yermack 2013), are determined. For comparability, we calculate the fiat equivalent that applied at the time when the crowdfunding process closed. ${ }^{3}$

Independent variables. Team size signifies the number of team members listed on the official website of each project. Team network represents the adjusted LinkedIn network reach of the team. We calculate the average LinkedIn network of all team members in relation to the number of team members who actually have a LinkedIn account. Advisors means the number of project advisors who are listed on the project website.

We use three different score variables (business model: Infrastructure; business model: Financial; and business model: Utility) to assess the quality of the business model of each project. For this purpose, we had an expert evaluate each project. The expert assigned a score of zero, one, or two for the three business model categories for each project. More specifically, the expert was asked to rate the quality of the projects' tokenized business model with regard to the (1) creation of infrastructure, like protocols that other projects can build on or networks where users can interact with each other; (2) the financial value that a tokenized business model unlocks, like a payment token or cryptocurrency-backed debit card system; and (3) the utility of the underlying token model. Utility represents the overall value that a token brings to a service, an ecosystem, or a network.

Whitepaper: Exists is a dummy variable that indicates the availability of a whitepaper for each project. There is no business standard for the actual contents of a whitepaper, which is why the overall quality can vary greatly. The use of whitepapers in the ICO ecosystem is based on the fact that Bitcoin was introduced in a whitepaper and very successful ICO projects, like Ethereum, also issued whitepapers (Nakamoto 2008; Buterin 2014; Wood 2014). The variable Whitepaper: Score, our proxy of whitepaper quality, equals the sum of the number of pages and citations in the document.

Twitter score summarizes the level of activity of a project's Twitter account as the sum of the number of tweets and the number of followers of the project divided by 1000.

Control variables. The variable ICO duration represents the number of days between the start and the end of the ICO. Mollick (2013) shows that the duration of a crowdfunding campaign can have a negative effect, as longer duration could be due to a lack of market confidence.

We assigned each project to one of six industry dummy variables: Financial (financial sector), Blocknet (blockchain network/infrastructure project), Media (media and communications sector), Gambling (gambling and casino projects), Gaming (gaming projects), and Cloud computing (cloud computing and cloud storage projects).

Team dispersion captures the number of different home countries represented among the team. This way, we can access the effects of centralized processes in project decisions (Mollick 2013) and the decentralized collaboration approach favored by open-source software projects (Belleflamme et al. 2014).

The Facebook score is calculated as the number of likes of the project's Facebook page divided by 1000. Reddit is an online forum where projects can start sub forums to discuss and rate articles and posts. ICO projects usually have their own Reddit page to interact with their community. The variable, Reddit score, consists of the number of subscribers to a project's subpage divided by 1000. Bitcointalk is a forum for projects related to cryptocurrencies where most ICO projects have an announcement thread. The Bitcointalk score is calculated as the number of total reads and the average number of posts per day of the full project's sub forum divided by 1000.

3 The example of the project, Digix Global, illustrates the effects of cryptocurrency price fluctuations. The project raised 462,719 Ether in March 2016, worth around \$5.5 million at the time. Thanks to the cryptocurrency price increase, the projects' funds were worth around \$132 million only two years later (https://etherscan.io/address/ 0xf0160428a8552ac9bb7e050d90eeade4ddd52843). 


\section{Results}

\subsection{Descriptive Statistics}

To show the evolution of ICOs and ICO funding, the projects were classified in quarters based on the end date of their ICO (see Figure 2). As the last ICO recorded ended on 3 August 2017, the numbers for the third quarter of that year were extrapolated linearly from the first 33 days of the quarter. The data exhibits a strong upward trend, driven especially by the 2017 ICOs. This trend holds both for the number of ICOs and the average amount raised. Before 2017, the funding amount was dominated by a few large projects, especially The DAO in Q2/2016. We thus see evidence of skewness, as also indicated by the large discrepancy between the average ( $\$ 6.5$ million) and median ( $\$ 0.4$ million) amount raised per ICO and the large standard deviation of $\$ 23.6$ million. A Gini coefficient of $86.7 \%$ also suggests that the distribution is strongly concentrated. We respond to this skewness by using the log of funds as our dependent variable (Manning and Mullahy 2001).

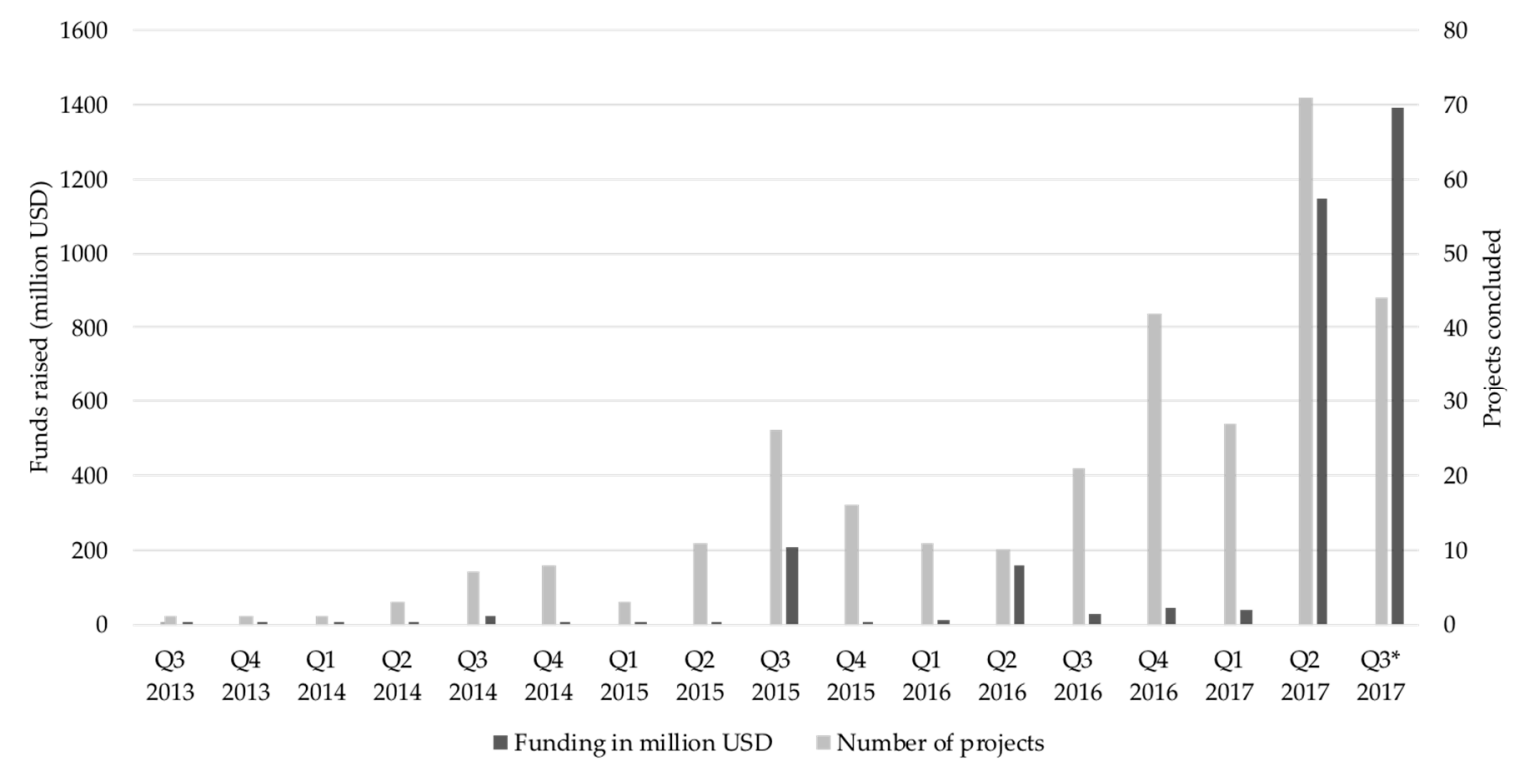

Figure 2. Number of ICOs and ICO funding in million US-dollars over time. Q3* 2017 has been interpolated for the remaining part of the quarter.

In terms of industries, most of the projects in our dataset can be assigned to the financial sector $(43.5 \%)$, followed by blockchain network and infrastructure projects $(13.6 \%)$, media and communications $(12.5 \%)$, gambling $(5 \%)$, and gaming $(4.3 \%)$. The classification by industries was conducted manually and is clearly open to debate as many projects could be allocated to multiple sectors. For example, gaming and gambling often overlap, and the sector of cloud computing and storage $(2.9 \%)$ is not much different from blockchain network or infrastructure projects.

Table 1 provides an overview of the descriptive statistics. The mean amount of funds raised was $\$ 6.5$ million, with a minimum of $\$ 25$ and a maximum of about $\$ 228$ million. The biggest project team had 46 members, while the average across all projects was 3.91. Team members possessed just below 100 LinkedIn contacts on average, while keeping in mind that 500 contacts is the maximal publicly shown amount. The average ICO duration was 26 days and the longest ICO took 906 days to complete. We were able to obtain whitepapers for $52 \%$ of all projects. 
Table 1. Descriptive statistics.

\begin{tabular}{lcccccc}
\hline \multicolumn{1}{c}{ Variables } & Obs. & Mean & Std. Dev. & Median & Min. & Max. \\
\hline Funds raised & 278 & $6,515,099$ & $23,241,612$ & 436,316 & 25 & $227,817,556$ \\
Log(Funds raised) & 278 & 5.471 & 1.315 & 5.64 & 1.4 & 8.36 \\
Team size & 278 & 3.910 & 6.141 & 0 & 0 & 46 \\
Team network & 278 & 97.477 & 147.021 & 0 & 0 & 500 \\
Advisors & 278 & 1.162 & 2.804 & 0 & 0 & 17 \\
Business model: & 278 & 0.662 & 0.779 & 0 & 0 & 2 \\
infrastructure & 278 & 0.644 & 0.69 & 1 & 0 & 2 \\
Business model: financial & 278 & 0.651 & 0.72 & 1 & 0 & 2 \\
Business model: utility & 276 & 26.070 & 62.817 & 15 & 0 & 906 \\
ICO duration & 276 & 0.996 & 0.647 & 1.48 & 0 & 2.957 \\
Log(ICO duration) & 278 & 13.230 & 17.601 & 2.5 & 0 & 131 \\
Whitepaper: score & 277 & 0.520 & 0.501 & 1 & 0 & 1 \\
Whitepaper: exists & 278 & 4.750 & 9.714 & 2.025 & 0 & 115.21 \\
Twitter score & 278 & 3.332 & 13.755 & 0 & 0 & 143.213 \\
Facebook score & 278 & 1.211 & 8.062 & 0.002 & 0 & 98.033 \\
Reddit Score & 278 & 117.681 & 266.287 & 25.85 & 0 & 2379.9 \\
Bitcointalk Score & 278 & 0.414 & 0.493 & 0 & 0 & 1 \\
Financial & 278 & 0.133 & 0.340 & 0 & 0 & 1 \\
Blocknet & 278 & 0.112 & 0.315 & 0 & 0 & 1 \\
Media & 278 & 0.054 & 0.226 & 0 & 0 & 1 \\
Gambling & 278 & 0.054 & 0.226 & 0 & 0 & 1 \\
Gaming & 278 & 0.216 & 0.146 & 0 & 0 & 1 \\
Cloud Computing & 278 & 1.040 & 1.628 & 0 & 0 & 9 \\
Team dispersion & $1 \mathrm{ICO}$ & & & 0 & 0 \\
\hline
\end{tabular}

${ }^{1}$ If ICO duration $>0$, then $\log ($ ICO duration), else 0 .

\subsection{Multivariate Results}

The multivariate results are based on four models, which we estimate by ordinary least squares (OLS. The results are reported in Table 2. In models 1 and 2, we added the variable, ICO duration, as a control variable to all independent variables to observe any effects of the length of the campaigns, while in model 2, we additionally added the six industry dummies to control for any influence of business sectors. In model 3, we added the variable $\log$ (ICO duration) to account for any heteroscedasticity, as there is substantial variation in ICO duration. The social media control variables are introduced in model 4 , as is team dispersion, to check for any effects of the degree of business centralization. Models 1 and 3 have $F$ values of 39.48 and 39.01 and adjusted $R^{2}$ values of 0.5857 and 0.5831 , respectively, suggesting a reasonable fit. The fourth model has a lesser fit, at $\mathrm{F}=30.79$ and adjusted $R^{2}=0.5854$. The second model has the highest adjusted $R^{2}(0.6021)$ and, being based on the largest number of different variables, the lowest $\mathrm{F}$ value (26.8).

In models 1,3, and 4, we find a significant, but small, positive influence of team size, while all four models predict a highly significant, but small, positive influence of the team network and a highly significant positive influence of the number of advisors on the funds raised. The existence of the whitepaper has a highly significant positive impact across all models, while for whitepaper: Score we find a positive but insignificant coefficient.

Regarding the quality of the business idea, we find highly significant positive results for Business model: Financial in all fours models. For Business model: Utility, we find positive results that are significant at the $1 \%$-level in models 1,3 , and 4 . Model 2 returns a weaker association $(p<0.1)$. We also find a marginally significant positive effect of ICO duration in model 1. Interestingly, social media has no significant impact, with the coefficient signs being variously positive (Twitter and Facebook) and negative (Bitcointalk and Reddit). We find a negative impact of Team dispersion in model 4. Regarding the industry dummies in model 4 , the only significant result is a strongly negative one for financial projects. 
Table 2. Results of OLS regression models.

\begin{tabular}{|c|c|c|c|c|}
\hline Variables & Model 1 & Model 2 & Model 3 & Model 4 \\
\hline Team size & $\begin{array}{l}0.019 * \\
(0.075)\end{array}$ & $\begin{array}{c}0.016 \\
(0.123)\end{array}$ & $\begin{array}{l}0.018 * \\
(0.089)\end{array}$ & $\begin{array}{c}0.032 * * * \\
(0.009)\end{array}$ \\
\hline Team network & $\begin{array}{l}0.009 * * \\
(0.047)\end{array}$ & $\begin{array}{c}0.001^{* * *} \\
(0.008)\end{array}$ & $\begin{array}{l}0.001 \text { * } \\
(0.045)\end{array}$ & $\begin{array}{c}0.001 * * \\
(0.014)\end{array}$ \\
\hline Advisors & $\begin{array}{c}0.061^{* * *} \\
(0.007)\end{array}$ & $\begin{array}{c}0.061^{* * *} \\
(0.008)\end{array}$ & $\begin{array}{c}0.063^{* * *} \\
(0.006)\end{array}$ & $\begin{array}{c}0.055^{* *} \\
(0.016)\end{array}$ \\
\hline Business model: Infrastructure & $\begin{array}{c}0.043 \\
(0.614)\end{array}$ & $\begin{array}{l}-0.034 \\
(0.696)\end{array}$ & $\begin{array}{c}0.048 \\
(0.573)\end{array}$ & $\begin{array}{c}0.093 \\
(0.288)\end{array}$ \\
\hline Business model: Financial & $\begin{array}{c}0.358^{* * *} \\
(0.000)\end{array}$ & $\begin{array}{c}0.395^{* * *} \\
(0.000)\end{array}$ & $\begin{array}{c}0.364^{* * *} \\
(0.000)\end{array}$ & $\begin{array}{c}0.391 * * * \\
(0.000)\end{array}$ \\
\hline Business model: Utility & $\begin{array}{c}0.265^{* * *} \\
(0.005)\end{array}$ & $\begin{array}{l}0.178^{*} \\
(0.065)\end{array}$ & $\begin{array}{c}0.252^{* * *} \\
(0.008)\end{array}$ & $\begin{array}{c}0.266^{* * *} \\
(0.005)\end{array}$ \\
\hline Whitepaper: Score & $\begin{array}{c}0.005 \\
(0.291)\end{array}$ & $\begin{array}{c}0.004 \\
(0.321)\end{array}$ & $\begin{array}{c}0.005 \\
(0.279)\end{array}$ & $\begin{array}{c}0.004 \\
(0.367)\end{array}$ \\
\hline Whitepaper: Exists & $\begin{array}{c}0.806^{* * *} \\
(0.000)\end{array}$ & $\begin{array}{c}0.811^{* * *} \\
(0.000)\end{array}$ & $\begin{array}{c}0.783 * * * \\
(0.000)\end{array}$ & $\begin{array}{c}0.829^{* * *} \\
(0.000)\end{array}$ \\
\hline Twitter score & $\begin{array}{c}0.008 \\
(0.169)\end{array}$ & $\begin{array}{c}0.005 \\
(0.410)\end{array}$ & $\begin{array}{c}0.008 \\
(0.200)\end{array}$ & $\begin{array}{c}0.011 \\
(0.148)\end{array}$ \\
\hline Bitcointalk score & - & - & - & $\begin{array}{l}-0.000 \\
(0.446)\end{array}$ \\
\hline Facebook score & - & - & - & $\begin{array}{c}0.001 \\
(0.776)\end{array}$ \\
\hline Reddit score & - & - & - & $\begin{array}{l}-0.001 \\
(0.850)\end{array}$ \\
\hline ICO duration & $\begin{array}{l}0.001 \text { * } \\
(0.083)\end{array}$ & $\begin{array}{c}0.001 \\
(0.208)\end{array}$ & 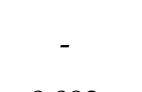 & - \\
\hline Log(ICO duration) & - & - & $\begin{array}{c}0.093 \\
(0.274)\end{array}$ & - \\
\hline Team dispersion & - & - & - & $\begin{array}{c}-0.105^{* *} \\
(0.039)\end{array}$ \\
\hline Blocknet & - & $\begin{array}{c}0.046 \\
(0.801)\end{array}$ & - & - \\
\hline Financial & - & $\begin{array}{c}-0.462 * * * \\
(0.000)\end{array}$ & - & - \\
\hline Media & - & $\begin{array}{c}-0.275 \\
(0.149)\end{array}$ & - & - \\
\hline Gambling & - & $\begin{array}{l}-0.097 \\
(0.696)\end{array}$ & - & - \\
\hline Gaming & - & $\begin{array}{c}0.041 \\
(0.869)\end{array}$ & - & - \\
\hline Cloud computing & - & $\begin{array}{c}0.455 \\
(0.227)\end{array}$ & - & - \\
\hline F & 39.48 & 26.8 & 39.01 & 30.79 \\
\hline Adj. $R^{2}$ & 0.5857 & 0.6021 & 0.5831 & 0.5854 \\
\hline
\end{tabular}

$*, * * * * *$ indicates significance at $0.05,0.01$ and 0.00 respectively.

\section{Discussion}

\subsection{Implications for Theory}

The exponential growth in ICO funding may be due to the "free money effect" or "house money effect" (Thaler and Johnson 1990). Early investors in Bitcoin or Ethereum reaped very large gains of many thousands of percent (depending on their entry, of course) that allowed them to invest large sums into ICOs. According to Zelizer (1994) Social Meaning of Money theory, money is treated differently depending on its context. This would imply that money won by investing in cryptocurrencies is not seen as neutral, but as tied to the same market. Compared to money gained in other markets, early 
cryptocurrency winners are more likely to invest large sums in ICOs. Another reason might reinforce this house money effect: Compared to gambling, early cryptocurrency investors might not perceive their gains as pure luck, but rather as the fruits of investing in a technological breakthrough. As early supporters, they are likely to reuse their funds to foster this technology. The analysis has shown that most funds are raised in a few very large ICOs that appear to attract most investor interest.

The results of the multivariate analysis support some of our hypotheses. Especially, H1, the conjectured positive relationship between human capital and funds raised, is supported by all four models in the form of significant positive effects of team size, team network size, and the number of advisors. This confirms our hypothesis that a larger network and thus greater human capital supports ICO success, in line with the corresponding literature on venture capital (Florin et al. 2003; Stuart et al. 1999), crowdfunding (Ahlers et al. 2015), and ICOs (Fisch 2019).

We also found support for $\mathrm{H} 2$ regarding the quality of a project in all four models, as there are significant correlations between funds raised on the business model in regards to financial and utility aspects. This finding suggests that investors, at least to some extent, rationally pick those ICOs which signal strong quality, rather than blindly distributing their funds across the available ICOs. This finding is in line with existing research on ICOs (Fisch 2019; Amsden and Schweizer 2018). Interestingly, we did not find significant results for the third variable, infrastructure. We suggest that investors may possess some form of knowledge to evaluate the quality of a business model.

Furthermore, we found a strong influence of whitepaper existence and thus some support for $\mathrm{H} 3$ of a positive relationship between project elaboration and funds raised. Yet, no significant effect was found for the whitepaper score. This suggests that what ICO investors value is not so much a convincing (technical) whitepaper, but rather the quality of the business model in general. This could be a sign that investors expect a whitepaper to be available, but do not actually read it. Our research confirms that the actual level of preparedness in form of a well-structured business plan promotes ICO success, as shown by Chen et al. (2009) for VC investment decisions.

Our hypothesis, $\mathrm{H} 4$, a positive relationship between social media presence and funds raised, failed to find any significant support across all social media variables. Twitter has a very small positive impact in all four models, as does Facebook, when included in model 4. Both Bitcointalk and Reddit yield insignificant and negative results. There are two reasons why a negative sign on these two variables is actually not surprising: (1) Whenever a project is exposed to rumors about illegitimacy or fraud, a lot of additional posts are generated, resulting in a high score; (2) projects that occurred towards the start of our sample period tend to raise less capital (by virtue of the growth trend we found), but have had more time to accumulate posts and thus have a higher score. ${ }^{4}$ If for these reasons we disregard Bitcointalk and Reddit and thus only interpret it as a proxy for social media attention the Twitter score, as it only comprises followers and project tweets, but not community posts, our result confirms the finding from the venture capital and crowdfunding literature that social media presence has a positive impact on financing campaigns. The finding furthermore suggests that entrepreneurs looking for funding via an ICO should devote attention to social media (Solomon et al. 2012; Sprenger et al. 2014).

In general, we show that investor behavior in ICOs shows similarities to the VC and crowdfunding markets. This suggests that ICOs may need to be integrated into the research on corporate finance. Our research adds to the literature of signaling theory by showing that ICO startups use certain types of information, like human capital characteristics, business model quality, and project elaboration, to signal their quality to campaign contributors.

4 Instead, the number of posts until the end of the ICO phase should have been used to determine the social media scores. Yet, this data is virtually impossible to retrieve automatically for past years. 


\subsection{Implications for Practice}

The blockchain technology is said to hold massive disruptive power for various industries, and to entail groundbreaking changes to numerous aspects of our lives. Startup funding is clearly among the affected fields. If the relevant players, including VC funds, startups, and business angels, are aware of the technology's disruptive potential and learn to harness it to improve current processes or to develop new business models, it can be a highly valuable tool for raising funds.

Furthermore, blockchain can potentially change the way in which businesses are managed and organized. Yet, before concrete action can be taken, companies need to familiarize themselves with the challenges and risks of the technology. In the financial industry, a broad utilization of blockchain is expected in no more than three to five years, so other industries need to start preparing for it.

The fact that companies are able to raise money without the need to offer any form of equity, voting rights, or profit participation in return could herald a new era of corporate financing. If ICO funding keeps growing, traditional methods of corporate finance may have to adapt in some form.

Several aspects of the ICO market suggest that a bubble is emerging. Blockchain-based ICOs and their underlying decentralized approach represent an innovative technology, and innovation lay at the root of the financial bubbles in new economy stocks (Pastor and Veronesi 2009), the Mississippi Bubble, the South Sea Bubble, and the Dutch Windhandel (Frehen et al. 2013). Pástor and Veronesi (2006) show that stock prices in innovative industries grow irrationally high and predict that their price falls once the uncertainty about the technology is resolved. The market for ICOs does fit clientele models as it features both arbitrageurs (informed investors) and noise traders (uninformed investors) (Frehen et al. 2013). Very high returns and rapid market growth constitute additional evidence of a price bubble emerging, which asset managers need to account for in their risk analysis (Lee and Phillips 2016).

\subsection{Limitations}

Regardless of the strengths of our study (e.g., the comprehensive data set of a wide range of ICOs starting from the very beginning in 2013), the following limitations should be mentioned. First, the ICO tokens issued by various projects represent very different things (Conley 2017). For instance, there are donation tokens, utility tokens (for different sorts of services and products), dividend tokens, and equity tokens. Moreover, a token can also provide two sorts of benefits at the same time. This variation may have unobserved effects on the amount of funds raised. We therefore encourage future studies to explicitly control for token characteristics and to compare the investment consequences of different kinds of tokens.

Second, the regulatory situation and legal status of the ICOs in our sample varied across countries and across time, potentially leading to uncontrolled effects on our observations. ICOs are such a novel phenomenon that there was and still is great regulatory uncertainty in many countries, allowing projects to sell tokens for large sums to investors without conducting Know-Your-Customer (KYC) procedures (Ante 2018). In 2017, the U.S. Securities and Exchange Commission (SEC) stated that the tokens sold in an ICO by the project The DAO (Jentzsch 2016) were indeed securities whose issuance in a crowdfunding campaign would have required a prospectus (SEC 2017a). The SEC additionally issued an investor bulletin that provides potential ICO investors with numerous warnings of investment fraud and a list of challenges that law enforcement face when investigating ICOs, including difficulties in tracing money flows, the international scope, the lack of central authority, and the risks and obstacles of freezing or securing virtual currency (SEC 2017b). On 11 December 2017, the SEC issued a cease-and-desist order to the Delaware-based company, Munchee Inc., that offered securities in their token sale, forcing the company to refund all investments and to abort its campaign. Munchee promised that the value of their offered MUN token would increase because of the company's work and that tokens would be traded on secondary markets. The token did not involve any profit participation mechanisms, such as buybacks or dividends (SEC 2017c). In other countries, ICO tokens may also represent securities or can alternatively also be considered currencies with or without securities characteristics (e.g., Germany). This unclear status may also have had an unobserved effect 
on our results. However, there is no reason to assume a systematic effect, so the results are unlikely to be biased.

As a mostly unregulated ecosystem, the ICO market is only beginning to mature. The first ICOs were carried out without incorporation or legal protection, which is why only limited information on these projects is available. Our dataset is likely missing a number of failed and abandoned ICO projects, so there is some selection bias in favor of successful projects. It is unclear whether and to what extent our results are influenced by this fact. As the market continues to grow rapidly, the relevant information is becoming much more accessible, so future research along these lines should not face the same problem.

Presales of tokens are a standard process used by many projects. Various different approaches, such as multi-stage presales and undisclosed presales, are used, which further reduces transparency in the market. More and more funds and venture capitalists are entering the ICO market and try to gain access to presale deals. Up until 2017, ICOs usually employed time-based bonus systems to incentivize investors to invest early, a practice that has now been replaced by presales. Our variable funds raised equals the sum of presale and main sale funding. Yet, we may not have captured all presale funding for some projects. As a limitation, we cannot observe whether presale success had any effect on the amount of funding raised in the ICO.

Some projects set minimum and maximum funding caps, while others try to raise as much capital as possible. Our study defined ICO success as the amount of capital that a project was able to raise, yet numerous projects met their funding targets in less than a day, so very likely they could have raised more capital. In these cases, our dependent variable may not adequately capture the true funding potential of a project or, in other words, the cap prevented our explanatory variables from taking full effect. For our dataset, we were unable to identify enough funding caps across all projects due to a lack of transparent data for historic campaigns. By implementing funding caps, the actual success of a project could potentially be defined more clearly. Still, most projects implement funding goals today, so their effects can be tested in future studies.

We have identified a small positive impact of the variable whitepaper score on funding success, while the existence of a whitepaper had a strong effect. Agrawal et al. (2014) show that crowdfunding campaigns tend to be more successful if a unique product or service can be easily explained. Therefore, whitepaper complexity could also impede funding success. Future research should therefore additionally control for the availability of a less complex version of the whitepaper, like a pitch deck.

Our model 4 yielded a negative connection between the funds raised and the geographical dispersion of a project's team members. This finding is at odds with the decentralized approach of the ICO ecosystem. Yet, the effect we found may really be driven by the existence of a collocated or virtual team (Powell et al. 2006) or by cultural differences (Burtch et al. 2013). To check for the second possibility, we conducted alternative calculations using geographical data, such as classifying projects according to cultural dimensions theory (Hofstede 1984) or evaluating whether the presence of a team member from China or eastern countries, like Russia, had any impact on ICO success. No significant results were found. We therefore encourage future research to look into this issue as the data quality continues to improve rapidly.

\section{Conclusions}

This study of the ICO phenomenon adds to existing research by evaluating how this new ecosystem compares to existing processes in VC and crowdfunding financing. We investigate this question from the perspective of the startups that are looking to raise money for their venture. Our findings suggest that the ICO market indeed exhibits close similarities to the classical markets of VC and crowdfunding: ICO success, as measured by the amount of capital raised, is positively related to human capital characteristics, business model quality, project elaboration, and social media presence. ICO contributors seem to invest rationally based on publicly available data. Yet, our findings regarding the relevance that investors assign to project elaboration and social media presence are to 
some extent inconclusive and require further research. The market for ICO is still underregulated and intransparent, with large information asymmetries between startups, contributors, and society. ICO success is subject to the same causalities and signals as classic VC and crowdfunding financing. We thus conclude that though ICOs are a new way of financing startups, they do constitute a new form of crowdfunding financing that will technically and legally move closer to traditional mechanisms as markets mature and regulators step in. It still remains to be seen to what extent the other markets will adapt towards the ICO market. By 2018, over $\$ 15$ billion has been raised in ICOs, so unless regulation puts a stop to it, the phenomenon is here to stay.

Our study adds to research in the field of ICOs as a novel form of fundraising for startups and paves the way for future research in this growing, but as yet under-researched area. Several questions warrant further research. First, longitudinal research is needed to examine ICOs over time and track their long-term development. A panel data set could yield more fine-grained insights into how the predictors influence ICO success and into the mechanisms behind each of the variables. Such research could also reveal the dynamics for certain variables, such as the influence of social media, advisors, or team composition. For instance, it can be assumed that social media may create a hype around certain ICOs. Longitudinal analyses of social media sentiment and funds raised over time could uncover the dynamics underlying the influence of social media. Future research should comprise time-series data on the social media channels of ICO projects to detect information cascades, under- or overpricing, and announcement effects.

Second, while our study has been conducted from a startup's perspective, looking at the determinants of the amount of funds raised, future research may investigate ICOs from an investor's perspective and focus on variables, such as returns, dividends, and market capitalization. For instance, our knowledge of investor strategies and the associated outcomes is very limited. In this regard, it would be interesting to investigate how investors allocate their funds in terms of, for example, industries, geography, and diversification, and what returns these strategies yield.

Third, we see a need to examine ICOs from a regulator's and a legal perspective, and the status of ICOs in society more generally. For instance, since tokens have different characteristics in different countries (being treated for example as securities, as a currency etc.), comparative research on the impact of such differential treatment is needed.

Fourth, given the amount of money at stake, we need to know how this form of funding can be institutionalized in a way that benefits society as a whole. We hope that our study will spark interest in these and related questions and trust that future research will address many of the as yet unresolved puzzles in the emerging token economy.

Supplementary Materials: The following are available online at http:/ /www.mdpi.com/1911-8074/11/4/80/s1, Datensatz ICO bereinigt.

Author Contributions: Conceptualization, L.A., P.S., I.F.; Data curation, L.A.; Formal analysis, L.A., P.S., I.F.; Investigation, L.A., I.F.; Methodology, L.A., P.S., I.F.; Project administration, L.A.; Resources, L.A.; Supervision, L.A. and I.F.; Validation, L.A., P.S., I.F.; Visualization, L.A.; Writing—original draft, L.A., P.S., I.F.; Writing—review and editing, L.A., I.F.

Funding: This research received no external funding.

Conflicts of Interest: The authors declare no conflict of interest.

\section{References}

Adhami, Saman, Giancarlo Giudici, and Stefano Martinazzi. 2018. Why do businesses go crypto? An empirical analysis of Initial Coin Offerings. Journal of Economics and Business, in press. [CrossRef]

Agrawal, Ajay, Christian Catalini, and Avi Goldfarb. 2014. Some simple economics of crowdfunding. Innovation Policy and the Economy 14: 63-97. [CrossRef]

Ahlers, Gerrit K. C., Douglas Cumming, Christina Günther, and Denis Schweizer. 2015. Signaling in equity crowdfunding. Entrepreneurship Theory and Practice 39: 955-80. [CrossRef] 
Ahlstrom, David, and Garry D. Bruton. 2006. Venture capital in emerging economies: Networks and institutional change. Entrepreneurship Theory and Practice 30: 299-320. [CrossRef]

Alexy, Oliver T., Joern H. Block, Philipp Sandner, and Anne L. J. Ter Wal. 2012. Social capital of venture capitalists and start-up funding. Small Business Economics 39: 835-51. [CrossRef]

Amit, Raphael, and Christoph Zott. 2001. Value creation in e-business. Strategic Management Journal 22: 493-520. [CrossRef]

Amsden, Ryan, and Denis Schweizer. 2018. Are Blockchain Crowdsales the New 'Gold Rush'? Success Determinants of Initial Coin Offerings. Available online: https: / / ssrn.com/abstract=3163849 (accessed on 1 August 2018).

Ante, Lennart. 2018. Cryptocurrency and crime. In The Money Laundering Market: Regulating the Criminal Economy. Edited by Killian J. McCarthy. London: Agenda Publishing.

Barrow, Colin, Paul Barrow, and Robert Brown. 2001. The Business Plan Workbook, 4th ed. London: Kogan Page.

Baum, Joel A. C., and Brian S. Silverman. 2004. Picking winners or building them? Alliance, intellectual, and human capital as selection criteria in venture financing and performance of biotechnology startups. Journal of Business Venturing 19: 411-36. [CrossRef]

Becker, Gary S. 1993. Nobel lecture: The economic way of looking at behavior. Journal of Political Economy 101: 385-409. [CrossRef]

Belleflamme, Paul, Thomas Lambert, and Armin Schwienbacher. 2014. Crowdfunding: Tapping the right crowd. Journal of Business Venturing 29: 585-609. [CrossRef]

Björkdahl, Joakim. 2009. Technology cross fertilization and the business model: The case of integrating ICTs in mechanical engineering products. Research Policy 38: 1468-77. [CrossRef]

Burtch, Gordon, Anindya Ghose, and Sunil Wattal. 2013. Cultural differences and geography as determinants of online pro-social lending. Business Research Paper, November 21.

Busenitz, Lowell W., James O. Fiet, and Douglas D. Moesel. 2005. Signaling in venture capitalists-New venture team funding decisions: Does it indicate long-term venture outcomes? Entrepreneurship Theory and Practice 29: 1-12. [CrossRef]

Buterin, Vitalik. 2014. Ethereum: A Next-Generation Smart Contract and Decentralized Application Platform. Available online: https:/ / github.com/ethereum/wiki/wiki/White-Paper (accessed on 20 September 2018).

Calia, Rogerio C., Fabio M. Guerrini, and Gilnei L. Moura. 2007. Innovation networks: From technological development to business model reconfiguration. Technovation 27: 426-32. [CrossRef]

Casadesus-Masanell, Ramon, and Joan Enric Ricart. 2010. From strategy to business models and to tactics. Long Range Planning 43: 195-215. [CrossRef]

Chen, Xiao-Ping, Xin Yao, and Suresh Kotha. 2009. Entrepreneur passion and preparedness in business plan presentations: A persuasion analysis of venture capitalists' funding decisions. Academy of Management Journal 52: 199-214. [CrossRef]

Chesbrough, Henry. 2010. Business model innovation: opportunities and barriers. Long Range Planning 43: $354-63$. [CrossRef]

Chesbrough, Henry, and Richard S. Rosenbloom. 2002. The role of the business model in capturing value from innovation: Evidence from Xerox Corporation's technology spin-off companies. Industrial and Corporate Change 11: 529-55. [CrossRef]

Cholakova, Magdalena, and Bart Clarysse. 2015. Does the possibility to make equity investments in crowdfunding projects crowd out reward-based investments? Entrepreneurship Theory and Practice 39: 145-72. [CrossRef]

Clayton, Jay. 2017. Statement on Cryptocurrencies and Initial Coin Offerings. Available online: https://www.sec. gov/news/public-statement/statement-clayton-2017-12-11 (accessed on 1 August 2018).

Coleman, Susan, and Alicia Robb. 2014. Access to Capital by High-Growth Women-Owned Businesses; Washington, DC: National Women's Business Council, pp. 1-32.

Colombo, Massimo G., Chiara Franzoni, and Cristina Rossi-Lamastra. 2015. Internal social capital and the attraction of early contributions in crowdfunding. Entrepreneurship Theory and Practice 39: 75-100. [CrossRef]

Conley, John P. 2017. Blockchain and the Economics of Crypto-Tokens and Initial Coin Offerings (No. 17-00008). Nashville: Vanderbilt University Department of Economics.

Cosh, Andy, Douglas Cumming, and Alan Hughes. 2009. Outside Entrepreneurial Capital. Economic Journal 119: 1494-533. [CrossRef] 
Cumming, Douglas J., Lars Hornuf, Moein Karami, and Denis Schweizer. 2016. Disentangling Crowdfunding from Fraudfunding. Max Planck Institute for Innovation and Competition Research Paper No. 16-09. Available online: https://www.researchgate.net/profile/Denis_Schweizer/publication/317997302 Disentangling_Crowdfunding_from_Fraudfunding/links/59f8ea17a6fdcc075ec99ba9/DisentanglingCrowdfunding-from-Fraudfunding.pdf (accessed on 8 August 2018).

De Filippi, Primavera, and Samer Hassan. 2018. Blockchain technology as a regulatory technology: From code is law to law is code. arXiv, arXiv:1801.02507.

Deakins, David, and Mark S. Freel. 2003. Entrepreneurship and Small Firms. London: McGraw Hill Higher Education.

Du, Qianzhou, Weiguo Fan, Zhilei Qiao, Gang Wang, Xuan Zhang, and Mi Zhou. 2015. Money talks: A predictive model on crowdfunding success using project description. Paper presented at Americas Conference on Information Systems (AMCIS), Puerto Rico, Territory, August 13-15.

Dubosson-Torbay, Magali, Alexander Osterwalder, and Yves Pigneur. 2002. E-business model design, classification, and measurements. Thunderbird International Business Review 44: 5-23. [CrossRef]

Fisch, Christian. 2019. Initial coin offerings (ICOs) to finance new ventures. Journal of Business Venturing 34: 1-22. [CrossRef]

Florin, Juan, Michael Lubatkin, and William Schulze. 2003. A social capital model of high-growth ventures. Academy of Management Journal 46: 374-84.

Frehen, Rik G. P., William N. Goetzmann, and K. Geert Rouwenhorst. 2013. New evidence on the first financial bubble. Journal of Financial Economics 108: 585-607. [CrossRef]

Gimmon, Eli, and Jonathan Levie. 2010. Founder's human capital, external investment, and the survival of new high-technology ventures. Research Policy 39: 1214-26. [CrossRef]

Griffin, Zachary J. 2012. Crowdfunding: Fleecing the American masses. Case Western Reserve Journal of Law, Technology and the Internet 4: 375. [CrossRef]

Hall, John, and Charles W. Hofer. 1993. Venture capitalists' decision criteria in new venture evaluation. Journal of Business Venturing 8: 25-42. [CrossRef]

Harrison, Richard, and Colin Mason. 1996. Developments in the promotion of informal venture capital in the UK. International Journal of Entrepreneurial Behaviour and Research 2: 6-33. [CrossRef]

Hellmann, Thomas, and Manju Puri. 2002. Venture capital and the professionalization of start-up firms: Empirical evidence. Journal of Finance 57: 169-97. [CrossRef]

Hofstede, Geert. 1984. Cultural dimensions in management and planning. Asia Pacific Journal of Management 1: 81-99. [CrossRef]

Hornuf, Lars, and Armin Schwienbacher. 2017. Market mechanisms and funding dynamics in equity crowdfunding. Journal of Corporate Finance 50: 556-74. [CrossRef]

Hsu, David H. 2007. Experienced entrepreneurial founders, organizational capital, and venture capital funding. Research Policy 36: 722-41. [CrossRef]

Iansiti, Marco, and Karim R. Lakhani. 2017. The truth about blockchain. Harvard Business Review 95: 118-27.

Jentzsch, Christoph. 2016. Decentralized Autonomous Organization to Automate Governance. Available online: https:/ / download.slock.it/public/DAO/WhitePaper.pdf (accessed on 8 August 2018).

Jin, Fujie, Andy Wu, and Lorin Hitt. 2017. Social Is the New Financial: How Startup Social Media Activity Influences Funding Outcomes. Academy of Management Proceedings 1: 13329. [CrossRef]

Joshi, Archana Prashanth, Meng Han, and Yan Wang. 2018. A survey on security and privacy issues of blockchain technology. Mathematical Foundations of Computing 1: 121-47. [CrossRef]

Kim, Jin-Hyuk, and Liad Wagman. 2016. Early-stage entrepreneurial financing: A signaling perspective. Journal of Banking and Finance 67: 12-22. [CrossRef]

Lechner, Christian, Michael Dowling, and Isabell Welpe. 2006. Firm networks and firm development: The role of the relational mix. Journal of Business Venturing 21: 514-40. [CrossRef]

Lee, Ji Hyung, and Peter C. B. Phillips. 2016. Asset pricing with financial bubble risk. Journal of Empirical Finance 38: 590-622. [CrossRef]

Lee, Choonwoo, Kyungmook Lee, and Johannes M. Pennings. 2001. Internal capabilities, external networks, and performance: A study on technology-based ventures. Strategic Management Journal 22: 615-40. [CrossRef]

Linn, Laure A., and Martha B. Koo. 2016. Blockchain for health data and its potential use in health it and health care related research. In ONC/NIST Use of Blockchain for Healthcare and Research Workshop; Gaithersburg: ONC/NIST. 
Macht, Stephanie A., and John Robinson. 2009. Do business angels benefit their investee companies? International Journal of Entrepreneurial Behavior and Research 15: 187-208. [CrossRef]

Malmendier, Ulrike, and Devin Shanthikumar. 2007. Are small investors naive about incentives? Journal of Financial Economics 85: 457-89. [CrossRef]

Manning, Willard G., and John Mullahy. 2001. Estimating log models: to transform or not to transform? Journal of Health Economics 20: 461-94. [CrossRef]

McGrath, Rita Gunther. 2010. Business models: A discovery driven approach. Long Range Planning 43: $247-61$. [CrossRef]

Mollick, Ethan R. 2013. Swept Away by the Crowd? Crowdfunding, Venture Capital, and the Selection of Entrepreneurs. Available online: https:/ / ssrn.com/abstract=2239204 (accessed on 1 August 2018).

Muzyka, Dan, Sue Birley, and Benoit Leleux. 1996. Trade-offs in the investment decisons of European venture capitalists. Journal of Business Venturing 11: 273-87. [CrossRef]

Nakamoto, Satoshi. 2008. Bitcoin: A Peer-to-Peer Electronic Cash System. Available online: https://bitcoin.org/ bitcoin.pdf (accessed on 12 June 2018).

Nevin, Sean, Rob Gleasure, Philip O'Reilly, Joseph Feller, Shanping Li, and Jerry Cristoforo. 2017. Social Identity and Social Media Activities in Equity Crowdfunding. Paper presented at 13th International Symposium on Open Collaboration, Galway, Ireland, August 23-25; p. 11.

Osgood, Ryan. 2016. The Future of Democracy: Blockchain Voting. In COMP116: Information Security, Tufts University Department of Computer Science. Available online: http:/ /www.cs.tufts.edu/comp/116/archive/ fall2016/rosgood.pdf (accessed on 5 August 2018).

Pástor, L'uboš, and Pietro Veronesi. 2006. Was there a Nasdaq bubble in the late 1990s? Journal of Financial Economics 81: 61-100. [CrossRef]

Pastor, Lubos, and Pietro Veronesi. 2009. Learning in financial markets. Annual Review of Financial Economics 1: 361-81. [CrossRef]

Powell, Anne, John Galvin, and Gabriele Piccoli. 2006. Antecedents to team member commitment from near and far: A comparison between collocated and virtual teams. Information Technology and People 19: 299-322. [CrossRef]

Puthal, Deepak, Nisha Malik, Saraju P. Mohanty, Elias Kougianos, and Gautam Das. 2018. Everything You Wanted to Know About the Blockchain: Its Promise, Components, Processes, and Problems. IEEE Consumer Electronics Magazine 7: 6-14. [CrossRef]

Robb, Alicia M., and David T. Robinson. 2014. The capital structure decisions of new firms. Review of Financial Studies 27: 153-79. [CrossRef]

Sandner, Philipp G., and Joern Block. 2011. The market value of R and D, patents, and trademarks. Research Policy 40: 969-85. [CrossRef]

Schwienbacher, Armin, and Benjamin Larralde. 2010. Crowdfunding of small entrepreneurial ventures. In Handbook of Entrepreneurial Finance. Oxford: Oxford University Press.

Scott, Brett. 2016. How Can Cryptocurrency and Blockchain Technology Play a Role in Building Social and Solidarity Finance? No. 2016-1. UNRISD Working Paper. Available online: https://www.econstor.eu/ bitstream/10419/148750/1/861287290.pdf (accessed on 22 August 2018).

SEC. 2017a. U.S. Securities and Exchange Commission. Investor Bulletin: Initial Coin Offerings. Available online: https:/ / www.sec.gov / oiea/investor-alerts-and-bulletins/ib_coinofferings (accessed on 17 August 2018).

SEC. 2017b. U.S. Securities and Exchange Commission. Securities and Exchange Commission, Securities Exchange Act of 1934, Release No. 81207/25 July 2017, Report of Investigation Pursuant to Section 21(a) of the Securities Exchange Act of 1934: The DAO. Available online: www.sec.gov/litigation/investreport/34-81207.pdf (accessed on 17 August 2018).

SEC. 2017c. U.S. Securities and Exchange Commission. Securities Act of 1933 Release no. 10445/11 December 2017. Administrative Proceeding File no. 3-18304. Order Instituting Cease-Anddesist Proceedings Pursuant to Section 8a of the Securities Act of 1933, Making Findings, and Imposing a Cease-and-Desist ordeR. Available online: www.sec.gov/litigation/admin/2017/33-10445.pdf (accessed on 17 August 2018).

Shafer, Scott M., H. Jeff Smith, and Jane C. Linder. 2005. The power of business models. Business Horizons 48: 199-207. [CrossRef]

Shepherd, Dean A., and Evan J. Douglas. 1999. Attracting Equity Investors: Positioning, Preparing and Presenting the Business Plan. Thousand Oaks: Sage. 
Solomon, Michael, Rebekah Russell-Bennett, and Josephine Previte. 2012. Consumer Behaviour. Melbourne: Pearson Higher Education AU.

Spence, Michael. 1973. Job market signaling. Quarterly Journal of Economics 87: 355-74. [CrossRef]

Sprenger, Timm O., Philipp G. Sandner, Andranik Tumasjan, and Isabell M. Welpe. 2014. News or noise? Using Twitter to identify and understand company-specific news flow. Journal of Business Finance and Accounting 41: 791-830. [CrossRef]

Stuart, Toby E., Ha Hoang, and Ralph C. Hybels. 1999. Interorganizational endorsements and the performance of entrepreneurial ventures. Administrative Science Quarterly 44: 315-49. [CrossRef]

Tankhiwale, Shekhar. 2009. Exploring the interrelationship between Telco business model innovation and the change in business process architecture. Journal of Telecommunications Management 2: 126-37.

Thaler, Richard H., and Eric J. Johnson. 1990. Gambling with the house money and trying to break even: The effects of prior outcomes on risky choice. Management Science 36: 643-60. [CrossRef]

Timmers, Paul. 1998. Business models for electronic markets. Electronic Markets 8: 3-8. [CrossRef]

Vismara, Silvio. 2016. Information cascades among investors in equity crowdfunding. Entrepreneurship Theory and Practice. [CrossRef]

Wheale, Peter Robert, and Laura Heredia Amin. 2003. "Bursting the dot. com" bubble': A case study in investor behaviour. Technology Analysis and Strategic Management 15: 117-36. [CrossRef]

Witt, Peter. 2004. Entrepreneurs' networks and the success of start-ups. Entrepreneurship and Regional Development 16: 391-412. [CrossRef]

Wood, Gavin. 2014. Ethereum: A secure decentralised generalised transaction ledger. Ethereum Project Yellow Paper 151: $1-32$.

Yang, Song, and Ron Berger. 2017. Relation between start-ups' online social media presence and fundraising. Journal of Science and Technology Policy Management 8: 161-80. [CrossRef]

Yermack, David. 2013. Is Bitcoin a Real Currency? An Economic Appraisal. No. w19747. Cambridge: National Bureau of Economic Research.

Zacharakis, Andrew, and Dean A. Shepherd. 2005. A non-additive decision-aid for venture capitalists' investment decisions. European Journal of Operational Research 162: 673-89. [CrossRef]

Zelizer, Viviana A. Rotman. 1994. The Social Meaning of Money. New York: Basic Books.

Zott, Christoph, Raphael Amit, and Lorenzo Massa. 2011. The business model: Recent developments and future research. Journal of Management 37: 1019-42. [CrossRef] 